\title{
The Application of the Problem-Based Learning Approach to English Class: Chinese-speaking Learners' Willingness to Communicate
}

\author{
Lu-Fang $\operatorname{Lin}^{1, *}$ \\ ${ }^{1}$ Institute of Applied English, National Taiwan Ocean University, Taiwan, R. O. C. \\ *Correspondence: Institute of Applied English, National Taiwan Ocean University, Keelung \\ 202, Taiwan, R. O. C. E-mail: annalin2038@gmail.com
}

Received: June 17, 2016 Accepted: July 11, 2017 Published: August 3, 2017

doi:10.5296/ije.v9i3.11414 URL: https://doi.org/10.5296/ije.v9i3.11414

\begin{abstract}
This study examined the effect of the integration of the problem-based learning (PBL) approach in English courses on Chinese-speaking university students' willingness to communicate (WTC). This study also examined whether there were possible differences in learners' WTC in terms of the gender variable. Two English classes in a Taiwanese university were randomly assigned to the PBL and teacher-lectured (TL) conditions. The PBL group with 43 participants received the PBL instruction in small group settings, whereas the TL group with 45 participants was fully provided with interpretations of teaching materials by the instructor and completed the tasks individually. The WTC scale, including seven subscales, was administered after the treatment. The results of two-way multivariate analysis of variance revealed that the PBL group significantly outperformed the TL group on the friend subscale, while the TL group demonstrated significant main effects on WTC subscales in terms of the gender variable.
\end{abstract}

Keywords: Chinese-speaking university students, English pedagogy, problem-based learning, willingness to communicate 


\section{Introduction}

With the rise of communicative methodology in the late 1970s, the role of learners in second language (L2) acquisition was increasingly emphasized. There are a great number of individual difference variables involved in L2 acquisition, among which willingness to communicate (WTC), a personality trait, has attracted recent attention (Cao, 2014). Further empirical investigations of L2 learners' WTC are needed and might contribute to "uncovering yet another vital aspect of the jigsaw of variables believed to underlie second language learning" (Pawlak \& Mystkowska-Wiertelak, 2015, p. 1). WTC is also necessary in the context of learning English as a foreign language (EFL) because it may direct the learner's efforts toward learning English effectively, and it may even decide the successfulness of English language usage. It is also an important part of the developing English expertise used in the workplace, and is especially pertinent in terms of fostering university students' future communication skills.

For decades, there have been calls for teachers to conduct learner-centered curricula at the tertiary level of education (Delialioğlu, 2012; Hmelo-Silver, 2004). English teaching methods may not only enhance learners' English proficiency, but also augment their WTC and their communication skills. In response to such calls, the problem-based learning (PBL) approach, which focuses on developing effective problem solvers, collaborative and self-directed learning, and interpersonal interaction, was integrated into English education in the EFL context. The pedagogical approach to facilitating WTC is currently underexplored and warrants further attention in the field of L2 acquisition. The purpose of this study was therefore to examine whether the PBL approach can improve EFL university students' WTC. The article concludes with proposing an educational interactive model for English courses administered in the EFL context.

\subsection{Willingness to Communicate}

WTC originally concerned first language people's tendency to approach or avoid initiating communication, and was represented as a personality trait (McCroskey \& Richmond, 1987). Previous studies found that frequency of communication is affected by a specific learner's WTC, and there seems to be a direct link between the decision to engage in interaction and the rate of L2 acquisition (Clément, Baker, \& MacIntyre, 2003; MacIntyre \& Charos, 1996; Yashima, Zenuk-Nishide, \& Shimizu, 2004). Peng (2013) indicated that in L2 educational contexts, the study of WTC is crucial in decoding learners' communication psychology and further promoting communication engagement in class.

Many studies have been conducted to explore the relationship between WTC and various variables, such as affective variables (e.g., communicative competence, attitudes, motivation, self-confidence, and desire to communicate with a specific person), social situation, and intergroup climate. These studies have lent support to the intertwined relationships between WTC and these variables, indicating that some specific learner variables have been found to exert a consistent impact on WTC (for detailed reviews see Cao, 2014, p. 790). WTC has been regarded as an influential factor in determining students' L2 achievement. The present study holds the assumption that learners with strong WTC can show initiative in learning and 
effectively receive training in English skills. This study used a teaching method to activate the learners' WTC.

The term WTC has been interpreted from different perspectives. In the field of L2 learning, WTC can be defined as "a readiness to enter into discourse at a particular time with a specific person or persons, using a L2” (MacIntyre, Dornyei, Clément, \& Noels, 1998, p. 547). Examining the age factor, MacIntyre, Baker, Clément, and Donovan (2003) found that students' second language WTC and frequency of communication in French increased from grades 7 to 8 , and that these increases were maintained between grades 8 and 9 . In addition, WTC has been widely investigated in the EFL context (Alemi Tajeddin, \& Mesbah, 2013; Aliakbari, Kamangar, \& Khany, 2016; Hsu, 2015; Nasiri, Suzani, Babamoradi, Mohammadi, 2016; Peng, 2012, 2013; Peng \& Woodrow, 2010; Yaghoubi, 2017). Several scales measuring L2 WTC have been documented in the literature (see the detailed review of the measurement of L2 WTC, Peng, 2013, p. 283).

Various WTC scales have been developed to measure first language WTC. Some researchers have used the WTC questionnaire developed by MacIntyre, Baker, Clément, and Conrod (2001). This instrument includes 27 items that measure the learners' WTC inside and outside of the classroom, and their orientation for language learning through the four skills of listening, speaking, reading, and writing. More recently, this scale has been used to examine the relationship between WTC and deculturation (Nasiri, Suzani, Babamoradi, \& Mohammadi, 2016), the contribution of EFL learners' linguistic self-confidence in their proficiency and language use anxiety to their WTC level (Ghanbarpour, 2016), and the relationship between critical thinking and WTC among EFL students (Yaghoubi, 2017). The abovementioned studies were conducted in the Iranian EFL context.

McCroskey and Richmond (1987) indicated that an individual's WTC can be influenced by contexts and receivers. They developed a WTC scale. With an emphasis on communicative functions in various social contexts, WTC in previous studies was considered with the following contextual elements: communication inside and outside the classroom, communication across different cultural groups who speak different mother languages, and communication in one's hometown, overseas, and workplace. McCroskey and Richmond (1987) developed the WTC scale by crossing three common types of receivers with four common communication contexts. McCroskey (1992) indicated that this scale represented "a cross-section of communication situations with which an individual might come in contact" (p. 21). Because the present study examined generic WTC in the Chinese-speaking community and the international workplace, instead of the performance of WTC in classroom settings and through the four language skills, the scale developed by McCroskey and Richmond (1987) seems to maximally match the current situation. To be broadly representative of communication situations, I used McCroskey's (1992) WTC scale to measure the learners' willingness to communicate in four types of communication contexts (group discussion, meetings, interpersonal conversations, and public speaking) and with three types of receivers (strangers, acquaintances, and friends).

Some researchers have used this scale to conduct empirical studies in L2 acquisition. 
Aliakbari, Kamangar, and Khany (2016) examined the simultaneous impact of anxiety, self-confidence, communicative competence, and international postures on Iranian EFL students' WTC. Alemi Tajeddin, and Mesbah (2013) administered a large-scale survey investigating the effects of individual differences on 431 Iranian EFL learners' WTC. The target learner variables included age, gender, academic major, personality type, English proficiency, length of studying, being abroad, and communicating with foreigners. Research on WTC in the EFL context has been widely conducted in a variety of countries. The results can differ from culture to culture.

From the reviewed literature on WTC, some researchers have agreed that it plays an essential role in language learning. However, the study focusing on developing teaching methods to facilitate the learner's WTC was still ignored. The present study delved into the contribution of English pedagogy to the field of WTC by integrating the PBL approach into English class in the EFL context.

\subsection{Application of the Problem-Based Learning Approach to Fostering WTC}

In this study, the problem-based learning (PBL) approach was a learner-centered, problem-based, and small-group learning pedagogic approach. One of the purposes of learning a second language is to enhance interpersonal and intergroup communication. The effectiveness of L2 learning can be maximized when learners are willing to participate in social interaction. The educational significance of PBL incorporates goals for students that are much broader than the memorization of subject knowledge in the textbook. As Savery and Dury (1996) indicated, the PBL pedagogy emphasizes learning via social interaction. During interpersonal interaction, students can perceive comprehensible input, receive immediate feedback, and negotiate the meaning of the target language.

In the field of language teaching approaches, the communicative language teaching (CLT) approach has caught great attention since the 1980s (Richards \& Rodgers, 2005). The educational objective of CLT is to augment language learners' communicative competence. Armed with the CLT theoretical foundation, the instructor designs the classroom activities to initiate communicative language use. When integrating the PBL approach to English class, one of the educational objectives is to cultivate the learner's communicative competence. In this way, the teacher and the learner play the roles different from those in the teacher-directed pedagogy. The teacher in a PBL curriculum acts as a facilitator to support students to solve the problem. As Lin (2017a, 2017b, 2017c) indicated, the teacher designed activities which offered just enough of a scaffold for the students to overcome this gap of second language knowledge construction and second language learning. On the other hand, the students are encouraged to use the target language in communicative contexts. The students are asked to complete the problem-solving task. The task of solving the problem can be regarded as a collaborative effort by all the students in the class. In most situations, the students are assigned into small groups to complete the task (Lin, 2017a, 2017b, 2017c).

Previous studies have demonstrated positive effects of PBL on interpersonal and intergroup communication. For example, PBL improved both ESL and native English-speaking students' communication abilities in cross-cultural workgroups (Allen \& Rooney, 1998). Furthermore, 
PBL integrated with Web-based technology has been found to effectively enhance students' interaction, motivation, and collaborative teamwork (ChanLin \& Chan, 2007; Tardadi, Taradi, Radi, \& Pokrajac, 2005). Comparing the effects of lecture-based and problem-based instructional approaches, Delialioğlu (2012) found that the PBL approach significantly fostered the participants' active participation, and the participants reported significantly higher time spent completing the task during the treatment than their counterparts.

PBL characterized by small-group interaction significantly fosters participants' positive interaction and group member communication (Sellow \& Ahlfeldt, 2005). By emphasizing L2 knowledge construction through sociocultural interaction, Lin (2017b) used the small-group format to conduct a PBL English reading curriculum. In Lin's (2017b) study, the PBL participants used a social website, Facebook, to communicate with each other after class. The results showed that the PBL curriculum combined with the small-group interaction activity provided the opportunity for EFL learners to communicate with each other, and effectively fostered their English reading ability. Moreover, Lin (2017c) indicated that the small group activities fostered the participants' active English learning attitudes in the PBL treatment better than did the non-PBL treatment.

PBL may foster the learners' WTC through mutual support in group work. In line with Allen and Rooney's (1998) concept of cooperative learning, the PBL approach is a task-centered activity requiring peer-to-peer interaction in small groups, interdependently structured to foster cooperation within groups, individual responsibility, and accountability. Taylor and Burgess (2003) stated that the positive value of PBL is group learning activities in which students enjoy the activities of searching out material from different sources and creating strategies for sharing the information. Given this as a goal, the individual participation in group interaction may eventually contribute to the cultivation of WTC. Thus, PBL pedagogy can meet the need to develop the learners' WTC. I therefore integrated the PBL approach into an EFL university English class to investigate its effect.

Reviewing the literature highlighted some gaps in the research. First, the PBL approach has been widely applied to education in various areas of expertise, but there is still a need to conduct explicit research in EFL education to verify the pedagogical effects. Second, WTC, recently considered as an important personality trait influencing L2 acquisition, has not been investigated in the research path of English teaching methods. Third, measuring WTC in EFL contexts appears to remain a challenging task (Peng, 2013). I scrutinized some scales to assess WTC in daily encounters in EFL contexts.

The present study investigated the impacts of the PBL approach on Chinese-speaking university students' WTC in the EFL context. To conduct a comparison study, I employed two teaching techniques, problem-based learning (PBL) and teacher lectures (TL). Researchers have used different WTC scales to investigate the influence of learner variables on WTC with mixed results. To provide language instructors with practical instructional knowledge to enhance English education in different culturally specific contexts, this study also examined whether there were possible differences in learners' WTC in terms of the gender variable after being exposed to different teaching techniques. 


\section{Macrothink}

The following research questions were addressed:

1. What are the main effects of the teaching technique and gender variables?

2. What are the interactions among the teaching technique and gender variables?

3. What are the participants' WTC after receiving the PBL and TL instructional techniques?

\section{Method}

\subsection{Participants}

The participants of this study were 88 university students in Taiwan. In total, 43 participants recruited from two English classes were trained with the problem-based learning (PBL) technique, and 45 participants recruited from one English class were instructed with the teacher-lectured (TL) technique. The PBL group had 23 males and 20 females, while the TL group consisted of 24 males and 21 females. Their mother language was Mandarin and they were learning English as a foreign language. They had studied English from approximately 12 to 15 years.

To fulfill the university's ocean-oriented educational goal, I adopted the textbook with a theme of marine creatures. The selected textbook was entitled, Cupid the Dolphin(Note 1). It was video-based material, published by the Footprint Reading Library (Waring, 2009).

\subsection{Data Collection}

The treatment section covered 5 weeks with one meeting per week, and 100 minutes for each meeting. The two instructional conditions were instructed with the same video-based material displayed on the Internet. Both instructional conditions were administered in the same language lab. All participants took the English proficiency (EP) test before the treatment. In addition, all of them filled out the WTC questionnaire after the treatment.

The PBL teaching scheme employed in this study was adopted from the previous studies by Lin (2017a, 2017b, 2017c). The teaching scheme administered in the earlier studies consisted of five phases, namely presenting the problem, reviewing the problem, examining the problem, re-examining the problem, and presenting the solutions. Table 1 summarizes the brief teaching scheme. 
Table 1. A Teaching Scheme for the PBL Treatment

\begin{tabular}{l} 
Phase Instructional activities \\
\hline 1 \\
The teacher presents and explores the students' prior knowledge and experience \\
related to the problem. \\
Each group sets up learning goals and the problem-solving schedule. \\
The teacher displays the assigned video on the Internet and leads the students to \\
discuss their prior experiences and conceptions related to the content of the \\
video. \\
Each group reviews the video to screen out the potential solutions to the problem. \\
Each group member is engaged in an Internet reading activity and a discussion \\
to identify the answers. \\
Each group leader as a representative reports their solution draft. \\
The teacher asks each group to read the problem carefully and to decompose the \\
elements contained in the problem. \\
Each group member analyzes the collected data and grasps some main ideas from the \\
collected data. \\
Each member exchanges the ideas with their partners and the leader collects them. \\
Each group leader reports the main points from the collected data. \\
The teacher leads the students to examine the problem again and introduces the \\
presentation rubrics. \\
Each group re-reads the collected data and looks for some other main points from the \\
collected data. \\
Each group draws an outline to organize the collected solutions and prepares an oral \\
presentation to display their solutions. \\
Each group uses the PowerPoint to present the solutions. \\
Each group member writes down the comments for other groups' presentation and \\
exchange with their partners. \\
The teacher integrates each group's solutions and demonstrates a solution sample. \\
The teacher provides feedback on each group's presentation. \\
5
\end{tabular}

Note. Some statements are cited from the weekly schedule in Lin's studies (2017b, pp. 23-24; 2017c, p. 114)

To facilitate communication among the participants, I conducted the program in small group settings with three to five students per group. The participants recruited their group members by themselves. Some groups were composed of members studying in the same department. Each group selected one group leader, who was responsible for leading the members to make sense of the content of the article, organized the meetings for collaborative learning, and distributed jobs to the members. The participants in Lin's (2017b) study used a social networking website (Facebook) as their communicative tool. Facebook was also applied in the present study. Lin (2017c) illustrated the framework of small group interaction in the PBL program and also presented the detailed requirement for group work in and out of class.

The PBL teaching scheme was abbreviated as follows: in the first week, the teacher proposed the problem related to the assigned video material, Cupid the Dolphin. The problem was, "As thousands of marine animals are stranded every year on the beach, what do you think are the reasons for their stranding?" The participants first viewed the assigned video material and 
figured out the main ideas of some sections and the meanings of some vocabulary from the textbook. In this phase, the instructor planned to ensure that the participants understood the content of the assigned material.

In the remaining four weeks, the classroom activity featured team work and small-group interaction. Each group used the Internet to search for the data and had a discussion to identify the solutions to the problem. The participants in each group read English articles and used English to record their solutions to the problem. The instructor walked around each group and provided interpretations of the English text on the Internet in relation to key concepts involved in solving the problem. The instructor requested each group to present their English written drafts at the end of each class. In some situations, the instructor provided some English vocabulary and phrases to help each group to write down their solutions.

To maintain the fluent procedure of the small-group discussion, the participants were allowed to use Mandarin Chinese to express and exchange their ideas. The instructor used both English and Mandarin Chinese to give guidance. After class, each group continued to have a discussion of the problem, undergo data collection, search for information, read the data and work on the preparation of oral presentation. The participants were encouraged to make decisions on every task together.

The TL group did not receive any PBL training. The teacher provided complete interpretations in class and the participants completed the tasks individually rather than in groups. The instruction component was structured as a series of teacher-centered reading and listening instructional sections in the following sequence of activities: article reading aloud, video text translation and interpretation, explanations of sentence structure and the meanings of vocabulary, and video replay for listening practice. The instructor asked individuals to respond in the abovementioned activities. The communication in class focused on the teacher and the learner. The instructor used English and Mandarin Chinese to offer the explanations and guide the participants to do the activities. At the end of each meeting, each participant did grammatical and vocabulary exercises.

\subsection{Instruments}

\subsubsection{General English Proficiency Test (GEPT)}

The test used in this study was a simulated GEPT test at the intermediate level. GEPT was developed and administered by the Language Training and Testing Center (LTTC) in Taiwan (LTTC, 2017). The GEPT was to measure the participants' reading and listening comprehension ability. The reading section containing 40 items in total involving answering multiple-choice questions on grammatical structures, vocabulary, and short passage comprehension. The listening section containing 45 items in total involved answering multiple-choice questions on short conversations. The detailed GEPT information can be viewed on the website (Level Descriptors_Intermediate, 2017). The maximum score for each test was 85, with each correct response worth one point. I calculated the Cronbach's alpha as the reliability statistic (Cronbach's $\alpha=.92$ ). 


\subsubsection{WTC Scale}

The WTC scale was adapted from McCroskey (1992, p. 18). The scale consisted of 20 items, eight of which were fillers. The twelve items were developed by crossing three common types of receivers with four common communication contexts. In total, the scale was composed of seven subscales. As recommended by McCroskey (1992), before filling out the scale, the participants were informed that they had completely free choice in mind to initiate or avoid communicating in the 20 receiver/context items. They could choose the percentage of times ranging from 0 to 100 to respond to each item. In addition, the participants were asked to recall their WTC during the instructional treatment.

The total WTC score and seven subscales were computed by following the scoring directions (McCroskey, 1992, p. 18). McCroskey (1992) reported this scale to be a valid and reliable tool: the estimates of internal reliability of the total score on this instrument ranged from .86 to .95; the obtained estimates for the context subscores ranged from .60 to .83 , and those for the receiver subscores ranged from .70 to .91 (p. 20). The reliability of the whole scale with 88 participants in this study was satisfactory at $\alpha=.82$.

\subsection{Data Analysis}

The present study was conducted to examine whether the two teaching techniques improved the participants' WTC. From the reviewed literature, gender can be an influential variable. The hypothesis is that WTC is affected by the difference in teaching techniques and gender. This is a ( $2 \times 2)$ factorial design with instructional technique (PBL versus TL) as one factor and gender (Male versus Female) as the second factor. A two-way multivariate analysis of variance (two-way MANOVA) was used to test this hypothesis. Instead of a univariate $F$ value, I would obtain a multivariate $F$ value (Wilks' $\lambda$ ) based on a comparison of the error variance/covariance matrix and the effect variance/covariance matrix.

In total, there were 88 respondents who completed the WTC scales. The independent variables were the instructional group (PBL and TL) and the gender (Males vs. Females), and the dependent variable consisted of the mean scores on the WTC scale (the total score, and seven subscores). To remove the effect of the two classes of participants' English proficiency before the treatment and to further decide whether the difference of the post-test means between the PBL and TL groups in WTC were statistically significant, the EP pre-test score was used as the covariate to control for any initial differences in the participants' English proficiency.

\section{Results}

\subsection{Main Effects and Interactions among the Instructional Technique and Gender on WTC}

The first two research questions were to examine the main effects and the interactions among the teaching technique and gender variables. 


\section{Ml Macrothink}

Table 2 presents the results of multivariate tests of the WTC scale for the two treatment groups. Two-way MANOVA was used to examine whether the teaching technique and gender has significant interaction effects on the WTC post-test while statistically controlling for the EP pre-test (covariate). Regarding the interaction between Gender and Instructional Group, the results of the multivariate tests demonstrated that there was no significant interaction of the two independent variables (Gender and Instructional Group) on the eight WTC dependent variables (the total score and seven scores of subscales). To understand the main effects of instructional group and gender on the WTC dependent variables, the Wilk's lambda was converted to $\mathrm{F}$ values and significance levels.

Table 2. Multivariate Tests of the WTC Scale and Subscales for the Instructional Groups and Gender

\begin{tabular}{|c|c|c|c|c|c|c|c|}
\hline Effect & & Value & $\mathrm{F}$ & Hypothesis & Error $\mathrm{df}$ & Sig. & $\begin{array}{c}\text { Partial } \\
\text { Eta } \\
\text { Squared }\end{array}$ \\
\hline Intercept & $\begin{array}{c}\text { Wilks' } \\
\text { Lambda }\end{array}$ & .014 & $700.867^{\mathrm{a}}$ & 8.000 & 77.000 & .000 & .986 \\
\hline $\begin{array}{c}\text { Instructional } \\
\text { Group }\end{array}$ & $\begin{array}{c}\text { Wilks' } \\
\text { Lambda }\end{array}$ & .788 & $2.588^{\mathrm{a}}$ & 8.000 & 77.000 & .015 & .212 \\
\hline Gender & $\begin{array}{c}\text { Wilks' } \\
\text { Lambda }\end{array}$ & .911 & $.941^{\mathrm{a}}$ & 8.000 & 77.000 & .488 & .089 \\
\hline $\begin{array}{c}\text { Instructional } \\
\text { Group } \\
\text { *Gender }\end{array}$ & $\begin{array}{l}\text { Wilks' } \\
\text { Lambda }\end{array}$ & .850 & $1.702^{\mathrm{a}}$ & 8.000 & 77.000 & .111 & .150 \\
\hline
\end{tabular}

Note. a. The statistic is an upper bound on $\mathrm{F}$ that yields a lower bound on the significance level. b. Design: Intercept + instructional group + gender + instructional group *gender

For the gender variable, there was no significant result $(F=.941, p=.488)$. As for the instructional group variable, Multivariate Tests yielded a significant difference $(F=2.588, p$ $=.015)$, indicating that among the PBL and TL participants' responses to the eight WTC dependent variables, there was at least one dependent variable's mean score which differed significantly.

As shown in Table 3, the results of Levene's test of homogeneity of variance yielded no significant differences between the two groups, indicating that the error variance of the WTC dependent variable is equal across groups. The mean difference is significant at the .05 level. The assumption of homogeneity was successfully met. 


\section{$\triangle$ Macrothink}

Table 3. Levene's Test of Equality of Error Variance

\begin{tabular}{lcccc}
\hline & $\mathrm{F}$ & $\mathrm{df1}$ & $\mathrm{df2}$ & Sig. \\
\hline Total Score & 1.101 & 3 & 84 & .353 \\
GDISS & 2.416 & 3 & 84 & .072 \\
MEET & .797 & 3 & 84 & .499 \\
INTERP & .306 & 3 & 84 & .821 \\
PUBSP & 1.703 & 3 & 84 & .173 \\
STRANG & .399 & 3 & 84 & .754 \\
ACQUA & 2.277 & 3 & 84 & .086 \\
FRIEND & 1.464 & 3 & 84 & .230 \\
\hline
\end{tabular}

Note. Design: Intercept + instructional group + gender + instructional group *gender

GDISS = Group Discussion; MEET = Meeting; INTER = Interpersonal conversation; PUBSP $=$ Public speaking; STRANG $=$ Stranger; ACQUA $=$ Acquaintance; FRIEND $=$ Friend. ${ }^{*} p$ $<.05$.

Table 4 presents a summary of the two-way MANOVA on the WTC total mean dependent variable. The results of the two-way MANOVA yielded no significant differences in the instructional group variable $(F=.009, p=.926>.05)$, or the gender variable $(F=.004, p$ $=.949>.05)$, and there was no significant interaction between the instructional group and gender variables $(F=2.938, p=.09>.05)$. The results showed that the participants in the PBL group did not show significantly greater WTC than their counterparts. That is, the PBL approach has no influential impact on elevating the participants' WTC as a whole.

Table 4. Summary of Two-way MANOVA on the WTC Total Mean Dependent Variable

\begin{tabular}{|c|c|c|c|c|c|c|}
\hline Source & $\begin{array}{l}\text { Type III } \\
\text { Sum of } \\
\text { Squares }\end{array}$ & df & $\begin{array}{l}\text { Mean } \\
\text { Square }\end{array}$ & $\mathrm{F}$ & Sig. & $\begin{array}{c}\text { Partial } \\
\text { Eta } \\
\text { Squared }\end{array}$ \\
\hline Corrected Model & $661.879^{\mathrm{a}}$ & 4 & 165.470 & 1.312 & .272 & .059 \\
\hline Intercept & 9030.341 & 1 & 9030.341 & 71.588 & .000 & .463 \\
\hline EP Pre & 227.290 & 1 & 227.290 & 1.802 & .183 & .021 \\
\hline Group & 1.107 & 1 & 1.107 & .009 & .926 & .000 \\
\hline Gender & .526 & 1 & .526 & .004 & .949 & .000 \\
\hline Group * Gender & 370.594 & 1 & 370.594 & 2.938 & .090 & .034 \\
\hline Error & 10469.900 & 83 & 126.143 & & & \\
\hline Total & 344801.778 & 88 & & & & \\
\hline Corrected Total & 11131.778 & 87 & & & & \\
\hline
\end{tabular}

Note. Group $=$ Instructional group. ${ }^{*} p<.05$ 
Furthermore, there were some significant differences shown in the seven subscales. Table 5 presents a summary of the two-way MANOVA on the mean scores of the seven WTC subscales. Regarding the main effect of the instructional group variable, there was a significant difference in the FRIEND independent variable $(F=12.19, p=.001<.05)$. The PBL group's mean score $(M=89.53)$ is significantly higher than that of the TL group $(M=$ 80.73). The finding suggests that the PBL approach significantly facilitates the participants' WTC, particularly when they communicate with their friends.

Table 5. Summary of Two-way MANOVA on the WTC Seven Dependent Variables

\begin{tabular}{|c|c|c|c|c|c|c|c|}
\hline Source & $\begin{array}{c}\text { Dependent } \\
\text { variables }\end{array}$ & $\begin{array}{l}\text { Type III } \\
\text { Sum of } \\
\text { Squares }\end{array}$ & df & $\begin{array}{c}\text { Mean } \\
\text { Square }\end{array}$ & $\mathrm{F}$ & Sig. & $\begin{array}{c}\text { Partial } \\
\text { Eta } \\
\text { Squared }\end{array}$ \\
\hline \multirow[t]{7}{*}{ Group } & GDISS & 48.868 & 1 & 48.868 & .187 & .667 & .002 \\
\hline & MEET & 88.184 & 1 & 88.184 & .306 & .581 & .004 \\
\hline & INTERP & 3.520 & 1 & 3.520 & .023 & .879 & .000 \\
\hline & PUBSP & 13.484 & 1 & 13.484 & .067 & .796 & .001 \\
\hline & STRANG & 1240.544 & 1 & 1240.544 & 3.415 & .068 & .040 \\
\hline & ACQUA & 5.100 & 1 & 5.100 & .016 & .898 & .000 \\
\hline & FRIEND & 1669.646 & 1 & 1669.646 & 12.190 & .001 & .128 \\
\hline \multirow[t]{7}{*}{ Gender } & GDISS & 280.559 & 1 & 280.559 & 1.071 & .304 & .013 \\
\hline & MEET & 665.079 & 1 & 665.079 & 2.311 & .132 & .027 \\
\hline & INTERP & 62.141 & 1 & 62.141 & .414 & .522 & .005 \\
\hline & PUBSP & 16.528 & 1 & 16.528 & .082 & .775 & .001 \\
\hline & STRANG & 283.793 & 1 & 283.793 & .781 & .379 & .009 \\
\hline & ACQUA & 6.231 & 1 & 6.231 & .020 & .888 & .000 \\
\hline & FRIEND & 143.309 & 1 & 143.309 & 1.046 & .309 & .012 \\
\hline \multirow[t]{7}{*}{$\begin{array}{l}\text { Group * } \\
\text { Gender }\end{array}$} & GDISS & 361.573 & 1 & 361.573 & 1.380 & .243 & .016 \\
\hline & MEET & 1556.628 & 1 & 1556.628 & 5.410 & .022 & .061 \\
\hline & INTERP & 43.340 & 1 & 43.340 & .289 & .593 & .003 \\
\hline & PUBSP & 630.122 & 1 & 630.122 & 3.136 & .080 & .036 \\
\hline & STRANG & 15.593 & 1 & 15.593 & .043 & .836 & .001 \\
\hline & ACQUA & 2089.782 & 1 & 2089.782 & 6.723 & .011 & .075 \\
\hline & FRIEND & 247.852 & 1 & 247.852 & 1.810 & .182 & .021 \\
\hline
\end{tabular}

Note . Group = Instructional group. GDISS = Group Discussion; MEET = Meeting; INTER = Interpersonal conversation; PUBSP = Public speaking; STRANG = Stranger; ACQUA = Acquaintance; FRIEND = Friend. ${ }^{*} p<.05$.

In addition, there were also some differences shown in the interactions of the instructional group and gender variables, especially in the MEET subscale $(F=5.41, p=.022<.05)$ and the ACQUA subscale $(F=7.723, p=.011<.05$; see Table 4$)$. As shown in Table 4, males in 


\section{$\triangle$ Macrothink}

the TL group outperformed their female counterparts both in the MEET and ACQUA independent variables. For the TL group, males' mean score on the MEET subscale (M= $64.06, \mathrm{SD}=3.47)$ is significantly higher than females' $(\mathrm{M}=48.30, \mathrm{SD}=3.71)$; males' mean score $(\mathrm{M}=75.80, \mathrm{SD}=3.58)$ on the ACQUA subscale is also significantly higher than females' $(M=64.82, \mathrm{SD}=3.83)$. This finding suggests that the male participants of the TL group were significantly more willing to communicate than their female counterparts in the meeting context and with acquaintances. For the PBL group, the gender variable yielded no significant impact on the participants' WTC in the four contexts or with the three types of receivers.

\subsection{The Participants' WTC after Receiving the PBL and TL Instructional Techniques}

The third research question was to explore the participants' WTC after receiving the PBL and TL instructional techniques. Each participant's responses to the 12 WTC items were categorized into high and low WTC according to McCroskey and Richmond's norms for high and low WTC scores (WTC Scale and Instructions, 2017). Furthermore, the frequencies of high and low categories of each WTC subscale were calculated (see Figure 1 and Figure 2 for the PBL and TL groups' high and low WTC of the seven subscales, respectively).

Regarding the PBL group, the FRIEND subscale has the highest frequency of high WTC. There were nine participants who had high WTC when communicating with their friends (see Figure 1). Consistent with the previous statistical results of the two-way MANOVA on the mean scores of the seven WTC subscales, the frequency result may further explain why the PBL group's mean score $(M=89.53)$ is significantly higher than that of the TL group $(M=$ 80.73) for the FRIEND subscale. Comparing the three types of receivers, the PBL participants were more willing to communicate with their friends than with strangers or acquaintances.

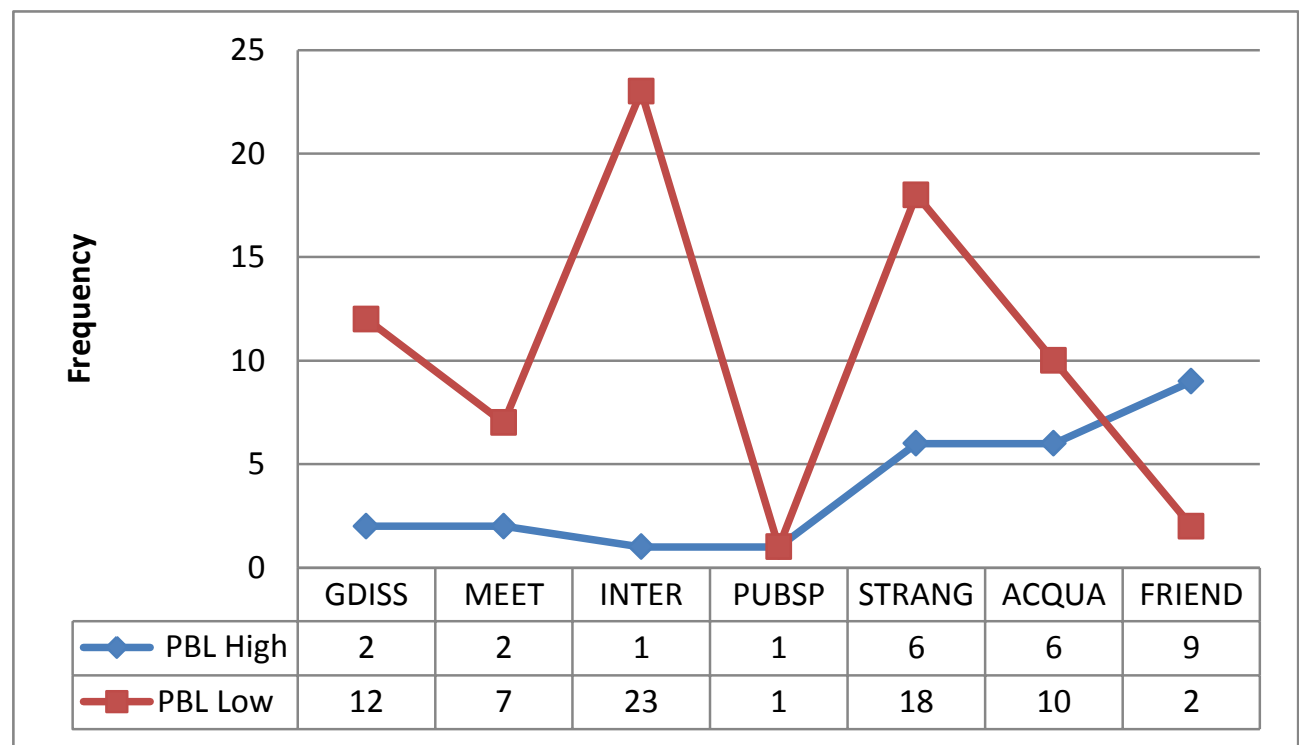

Figure 1. The PBL group's frequencies of high and low WTC for the seven subscales (PBL, $\mathrm{n}=43$ ). GDISS = Group Discussion; MEET = Meeting; INTER = Interpersonal conversation; PUBSP $=$ Public speaking; STRANG = Stranger; ACQUA = Acquaintance FRIEND = 


\section{MIMacrothink}

Friend.

On the other hand, the INTER subscale has the highest frequency of low WTC. There were 23 PBL participants with low WTC in the context of interpersonal conversations. Of the seven subscales, the frequencies of low WTC of the five subscales are higher than those of high WTC, namely GDISS, MEET, INTER, STRANG, and ACQUA. In the public speaking context, the frequencies of high and low WTC is equal (see Figure 1).

Regarding the TL group, the PUBSP subscale has the highest frequency of high WTC. There were seven participants with high WTC when communicating in a public speaking context. On the other hand, the INTER subscale also has the highest frequency of low WTC, and there were no TL participants with high WTC for this subscale. Of the seven subscales, the frequencies of low WTC of the six subscales are higher than those of high WTC. The exception is the PUBS subscale (see Figure 2).

In general, both the PBL and TL groups had higher frequencies of low WTC than those of high WTC on the GDISS, MEET, INTER, STRANG, and ACQUA subscales, respectively. Regarding the low WTC of the STRANG subscale, the PBL group had 3.6 times the frequency of the TL group. When communicating with strangers, the PBL participants demonstrated much lower WTC than their counterparts. Furthermore, 53\% of the PBL participants and $49 \%$ of the TL participants scored specifically low WTC on the INTER subscale.

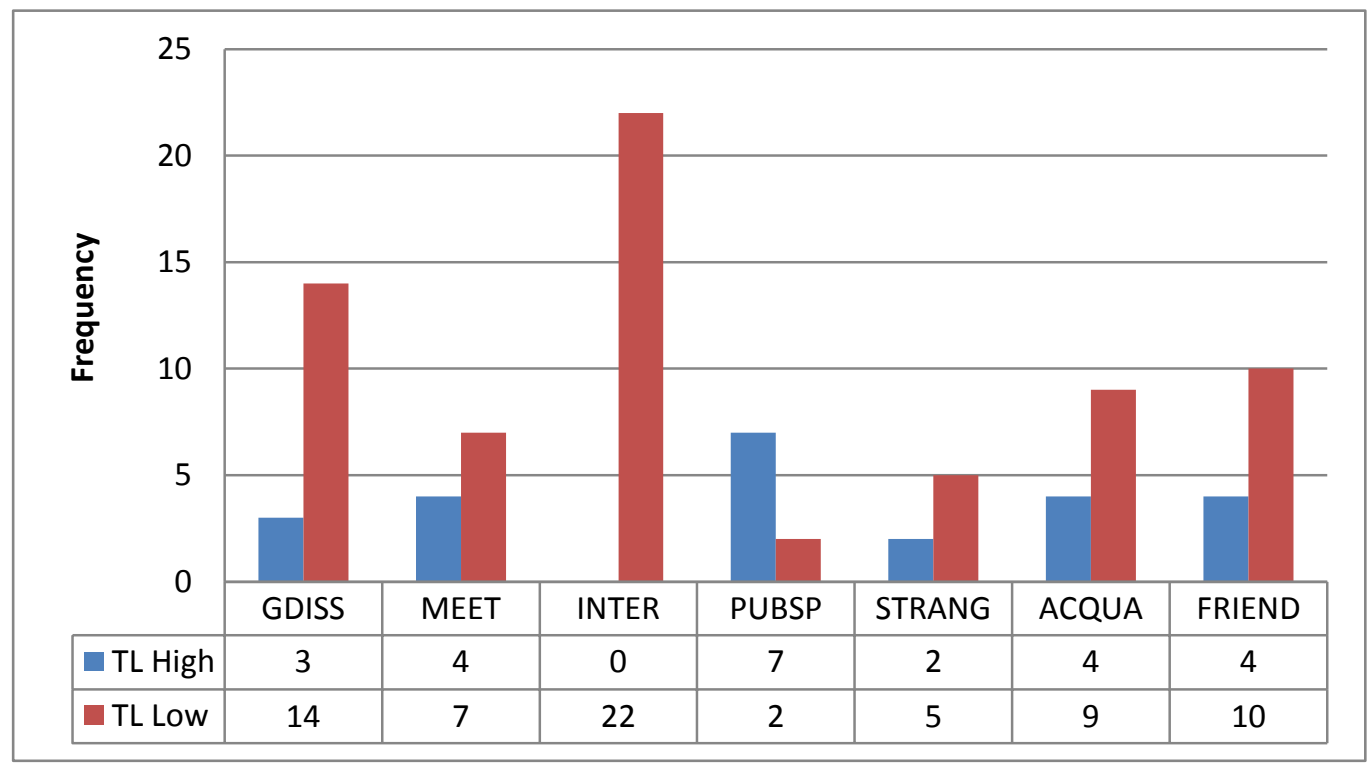

Figure 2. The TL group's frequencies of high and low WTC for the seven subscales (TL, $\mathrm{n}=$ 45). GDISS = Group Discussion; MEET = Meeting; INTER = Interpersonal conversation; PUBSP = Public speaking; STRANG = Stranger; ACQUA = Acquaintance; FRIEND = Friend. 


\section{Discussion}

The present study examined whether the PBL approach can significantly foster Chinese-speaking university students' WTC from the aspects of the communication contexts and the receivers. In general, the PBL participants demonstrated greater WTC than their counterparts when communicating with friends. Previous studies focusing on the effects of the PBL approach indicated that PBL progressively enhanced students' communication skills (Allen \& Rooney, 1998; Sellow \& Ahlfeldt, 2005). The results of the present study further offered specific evidence that PBL obviously fostered the participants' WTC with the partners they felt most familiar with. This significant result can be explained by the following reasons.

First, this is probably because the PBL teaching procedure featured small-group interaction. As Lin (2017b) explained, "social communication in small groups offers supportive scaffolding in the PBL group" (p. 19). In this study, the participants in the PBL group were encouraged to interact with each other both in and after class. Through the small-group discussion, each participant was assigned a task to complete and hence frequently joined the process of learning in collaboration their group members. In this way, small group interaction offered opportunities for the participants to cultivate friendship with each other. It appears that such a small-group model established an intimate connection among the participants. Each participant was hence bounded together in a group and learned from each other in an environment supportive of group interaction.

Second, the group facilitator played an essential role. The group facilitators in the PBL group may have exerted considerable influence on his/her group members. As Taylor and Burgess (2003) indicated, the group facilitator acts both as "a role model and an enabler of positive practice" (p. 112), demonstrating English skills that are essential to the English curriculum and ensuring that all members have equal opportunities to participate and hence to contribute their ideas at some point in each meeting. In addition, the group leader acted like a liaison officer who maintained communications, contact or liaison with their members. Each participant likely had the chance to have contact with their group. This may result in the significant difference between the PBL and TL groups in the FRIEND subscale.

Third, the significant results can be attributed to the sufficiently supportive interpersonal environment for English learning provided in the PBL treatment. ChanLin and Chan (2007) indicated that collaborative efforts were observed from group interactions. As Lin (2017c) explained, "this small-group model builds up an intimate connection among learners, and consequently supports the learners in extending their English learning outside the classroom" (p. 121). Similarly, the findings of this study further illustrated that PBL leads to extra exploitation of peer support. In this study, the participants in small groups had the opportunity to request help from their group members for organizing their schedule to complete their assignments, something which did not exist in the TL condition because the TL participants probably seldom contacted each other after class. Consequently, the teacher-centered lectures may not have successfully fostered the individuals' WTC in the FRIEND subscale. 
The TL group in this study, on the other hand, demonstrated significant main effects on the WTC subscales in terms of the gender variable. The statistical results showed that, compared with the female participants of the TL group, the male participants obviously demonstrated greater WTC in the meeting context and with their acquaintances. These results are not consistent with those reported in previous studies. For example, Alemi, Tajeddin, and Mesbah (2013) reported that there was no significant difference between males' and females' WTC in the Iranian context. Conducting the WTC survey in the Canadian context, MacIntyre, Baker, Clément, and Donovan (2003) indicated that female students in junior high school had stronger WTC than males; there were no significant differences between females and males studying in the high school and the university. However, MacIntyre et al. (2003) further concluded that males' WTC increases as their age increases, while females' WTC decreases. This may explain why males in the TL group yielded significant results in the WTC subscales of meeting and acquaintance. This is because the TL participants in the present study were undergraduate students (sophomores, juniors, and seniors) and graduate students in the university.

In addition, the interpersonal relationship of the two subscales (meeting and acquaintance) is not similar to that of the friend subscale. After the treatment, the PBL group tended to develop an intimate friend relationship, while males in the TL group tended to be willing to communicate in a more public context and with persons not close to them.

Finally, the two instructional groups demonstrated a certain degree of low WTC according to the frequency results of the seven subscales. This result can be explained by Hsu's (2015) study. By investigating 354 Taiwanese university freshmen's attitudes toward oral participation in an English class, Hsu (2015) indicated that the participants tended to be passive learners in a communication-oriented pedagogy and demonstrated low overall involvement. The learners' WTC in English class is to some degree related to their willingness to speak in English. As such, most participants were probably not willing to talk too much due to their English speaking ability limitations.

\section{Conclusion}

This study investigated the effects of the PBL approach on EFL university students' WTC. Regarding the significant results, it was observed in this study that the PBL group showed significantly strong WTC with their friends. However, it should be noted that the male university students in the TL group also showed strong WTC in the meeting context and with their acquaintances. The first instructional recommendation is that the PBL pedagogy is suitable for developing EFL learners' WTC with their friends. Specifically, when the instructor intends to administer English oral communication practice in a PBL program, the instructor may set up small groups in which the members are familiar with each other. In this way, the learners can be trained to be willing to use English in a communicative context.

Second, the learners' WTC with different receivers in different contexts can be trained with 
teaching techniques oriented with different degrees of interpersonal interaction. "[C]ommunicative competence has been emphasized in the EFL context" (Lin, 2017a, p.18). In keeping with the emphasis on developing EFL learners' communicative competence, the English pedagogy suggests that learners be encouraged to be willing to communicate in various social contexts and with receivers of different levels of familiarity. In this study, the PBL and TL teaching techniques pertained to different interpersonal interaction models and yielded significant WTC results. The findings suggest that the participants in the two instructional groups showed different degrees of willingness to communicate. Language educators may consider the significant results concluded from both the PBL and TL groups to design second/foreign language curricula which bring together a range of English pedagogical practices, including collaborative learning and cultivation of communication willingness.

As in any social research, this study is also bound by some limitations. First, the study employed McCroskey's (1992) WTC scale to measure EFL learners' WTC. Pawlak and Mystkowska-Wiertelak (2015) pointed out that the nature of WTC in a second language is complex, and has a dynamic character during one communicative event. As discussed in the literature review section, the influential components of WTC have not yet been identified completely. In future, other factors can be added due to different pedagogical purposes. Second, the dependency of the findings on the WTC scale might have limited the results of the study. Thus, self-reports and observation data can be added in future research.

\section{Acknowledgement}

The research is partially financed by the National Science Council, Taiwan, under Grant NSC 101-2410-H-019-013.

\section{References}

Alemi, M., Tajeddin, Z., \& Mesbah, Z. (2013). Willingness to communicate in L2 English: Impact of learner variables. Journal of Applied Linguistics, 42-61.

Aliakbari, M., Kamangar, M., \& Khany, R. (2016). Willingness to Communicate in English among Iranian EFL Students. English Language Teaching, 9(5), 33-45. https://doi.org/10.5539/elt.v9n5p33

Allen, R., \& Rooney, P. (1998). Designing a problem-based learning environment for ESL students in business communication. Business Communication Quarterly, 61 (2), 48-55. https://doi.org/10.1177/108056999806100207

Cao, Y. K. (2014). A Sociocognitive Perspective on Second Language Classroom Willingness to Communicate, TESOL QUARTERLY, 48(4), 789-814. https://doi.org/10.1002/tesq.155 
ChanLin, L.-J., \& Chan, K.-C. (2007). Integrating inter-disciplinary experts for supporting problem-based learning. Innovations in Education and Teaching International, 44(2), 211-224. https://doi.org/10.1080/14703290701241026

Clément, R., Baker, S. C., \& MacIntyre, P. D. (2003). Willingness to communicate in a second language: the effects of context, norms, and vitality. Journal of Language and Social Psychology, 22(2), 190-209. https://doi.org/10.1177/0261927X03022002003

Delialioğlu, Ö. (2012). Student Engagement in blended learning environments with lecture-based and problem-based instructional approaches. Educational Technology \& Society, 15(3), 310-322.

Ghanbarpour, M. (2016). Willingness to communicate, linguistic self-confidence, and language-use anxiety: The Iranian EFL context. Theory and Practice in Language Studies, 6(12), 2265-2271. https://doi.org/10.17507/tpls.0612.05

Hmelo-Silver, C. E. (2004). Problem-based learning: What and how do students learn?. Educational Psychology Review, 16(3), 235-266. https://doi.org/10.1023/B:EDPR.0000034022.16470.f3

Hsu, W. H. (2015). Transitioning to a communication-oriented pedagogy: Taiwanese university freshman's view on class participation, System, 49, 61-72. https://doi.org/10.1016/j.system.2014.12.002

Level Descriptors (2017). Intermediate. [Online] Available: https://www.lttc.ntu.edu.tw/E_LTTC/E_GEPT/intermediate.htm

Lin, L. F. (2017a). English Grammar Instruction and the Problem-based Learning Approach: A Multiliteracies Perspective. The International Journal of Literacies, 24(1), 17-26. https://doi.org/10.18848/2327-0136/CGP/v24i01/17-26

Lin, L. F. (2017b). Integrating the Problem-based Learning Approach into a Web-based English Reading Course. Journal of Educational Computing Research. Advance online publication. https://doi.org/10.1177/0735633117705960

Lin, L. F. (2017c). Impacts of the Problem-based Learning Pedagogy on English Learners' Reading Comprehension, Strategy Use, and Active Learning Attitudes. Journal of Education and Training Studies, 5(6), 109-125. https://doi.org/10.11114/jets.v5i6.2320

LTTC (2017). About LTTC. [Online] Available: https://www.lttc.ntu.edu.tw/aboutthelttc.htm

MacIntyre, P. D., Baker, S. C., Clément, R., \& Conrod, S. (2001). Willingness to communicate, social support, and language learning orientations of immersion students. Studies in Second Language Acquisition, 23, 369-388. https://doi.org/10.1017/S0272263101003035

MacIntyre, P., Baker, S. C., Clément, R., \& Donovan, L. A. (2003). Sex and Age Effects on Willingness to Communicate, Anxiety, Perceived Competence, and L2 Motivation among Junior High School French Immersion Students. Language Learning, 53, 137- 
166. https://doi.org/10.1111/1467-9922.00226

MacIntyre, P. D., \& Charos, C. (1996). Personality, attitudes, and affect as predictors of second language communication. Journal of Language and Social Psychology, 15(1), 326. https://doi.org/10.1177/0261927X960151001

MacIntyre, P., Dornyei, Z., Clement, R., \& Noels, K. (1998). Conceptualizing willingness to communicate in a L2: A situational model of L2 confidence and affiliation. Modern Language Journal, 82, 545-562. https://doi.org/10.1111/j.1540-4781.1998.tb05543.x

McCroskey, J. C., \& Richmond, V. P. (1987).Willingness to communicate. In J. C. McCroskey \& J. A. Daly (Eds.), Personality and interpersonal communication (pp. 129-156). Newbury Park, CA: Sage.

McCroskey, J. C. (1992). Reliability and validity of the willingness to communicate scale. Communication Quarterly, 40(1), 16-25. https://doi.org/10.1080/01463379209369817

Nasiri, M., Suzani, M., Babamoradi, P., Mohammadi, N. (2016). On the relationship between willingness to communicate and decultuartion. Theory and Practice in Language Studies, 6(6), 1273-1278. http://dx.doi.org/10.17507/tpls.0606.18

Pawlak, M., \& Mystkowska-Wiertelak, A. (2015). Investigating the dynamic nature of L2 willingness to communicate. System, 50, 1-9. https://doi.org/10.1016/j.system.2015.02.001

Peng, J. (2012). Towards an ecological understanding of willingness to communicate in EFL classroom in China. System, 40(2), 203-213. https://doi.org/10.1016/j.system.2012.02.002

Peng, J. (2013). The challenge of measuring willingness to communicate in EFL contexts. Asia-Pacific Educational Research, 22(3), 281-290. https://doi.org/10.1007/s40299-012-0053-x

Peng, J. E., \& Woodrow, L. J. (2010). Willingness to communicate in English: A model in the Chinese EFL classroom context. Language Learning, 60, 834-876. https://doi.org/10.1111/j.1467-9922.2010.00576.x

Richards, J. C., \& Rodgers, T. S. (2005). Approaches and methods in language teaching. NY: Cambridge University Press.

Savery, J., \& Duffy, T. (1996). Problem based learning: An instructional model and its constructivist framework. In B. Wilson (Ed.), Constructivist Learning Environments: Case Studies in Instructional Design (pp. 135-148). Englewood Cliffs, NJ: Educational Technology Publications.

Sellow, D. D. \& Ahlfeldt, S. L. (2005). Fostering critical thinking and teamwork skills via a problem-based learning (PBL) approach to public speaking fundamentals. Communication Teacher, 19(1), 33-38. https://doi.org/10.1080/1740462042000339258

Taradi, SK., Taradi, M., Radic, K., \& Pokrajac, N. (2005). Blending problem-based learning 
with Web technology positively impacts student learning outcomes in acid-base physiology. Advances in physiology education, 29(1), 35-39. https://doi.org/10.1152/advan.00026.2004

Taylor, I., \& Burgess, H. (2003). Responding to 'non-traditional' students: an enquiry and action approach. In D. Boud \& G. I. Feletti (Eds.), The challenge of problem-based learning (pp. 103-116). London: Kogan Page Limited.

Waring, R. (Ed.). (2009). Cupid the Dolphin. Boston, Massachusetts: Heinle, Cengage Learning.

WTC Scale and Instructions (2017). Willingness To Communicate (WTC). [Online] Available: http://www.jamescmccroskey.com/measures/WTC.htm

Yaghoubi, A. (2017). Critical thinking and willingness to communicate among EFL students. Journal of Language Teaching and Research, 8(2), 375-381. https://doi.org/10.17507/jltr.0802.22

Yashima, T., Zenuk-Nishide, 1., \& Shimizu, K. (2004). The Influence of Attitudes and Affect on Willingness to Communicate and Second Language Communication. Language Learning, 54(1), 119-152. https://doi.org/10.1111/j.1467-9922.2004.00250.x

\section{Note}

Note 1. This textbook was adopted in Lin's (2017c) study. The websites presented in Lin's (2017c) study were introduced in the present study.

\section{Copyright Disclaimer}

Copyright for this article is retained by the author(s), with first publication rights granted to the journal.

This is an open-access article distributed under the terms and conditions of the Creative Commons Attribution license (http://creativecommons.org/licenses/by/3.0/). 